\title{
NATURALNESS IN ENGLISH: (A) THE GENITIVE, (B) THE PRONOUNS
}

In Slovenia, the natural syntax of the Klagenfurt brand has been extended to the study of the behaviour of (near-)synonymous syntactic expressions, here called syntactic variants. The work below is illustrated by the (morpho)syntax of the English genitive and the English pronouns. The language material is divided into consecutively numbered deductions in each of which the existence of a (morpho)syntactic state of affairs is predicted on the basis of apposite assumptions and Andersen's markedness alignment rules. The basic point: given two (morpho)syntactic variants, such that one of them shows feature $A$, and the other shows feature $B$, the theory can answer the question as to which of the two variants shows which of the two features $A$ and $B$.

\section{Introduction}

The subject-matter of my paper is a (language-universal) theory developed in Slovenia by a small group of linguists (under my guidance), who mainly use English, German, and Slovenian language material as the base of verification. Our work owes much to, and exploits, the (linguistic) Naturalness Theory especially as elaborated at some Austrian and German universities; cf. Mayerthaler (1981), Wurzel (1984), Dressler et al. (1987) and Dressler (2000). Naturalness Theory has also been applied to syntax, notably at the University of Klagenfurt; the basic references are Dotter (1990), Mayerthaler \& Fliedl (1993) and Mayerthaler et al. (1993; 1995; 1998). Within the natural syntax of the Klagenfurt brand, the Slovenian work group has constructed an extension that studies the behaviour of (near-)synonymous syntactic expressions, here called syntactic variants. Whenever two syntactic variants are included in the same naturalness scale, and consequently one variant can be asserted to be more natural than the other, something can be said about some grammatical properties of the two variants.

Within Naturalness Theory, Mayerthaler (1981:10 et passim) distinguishes semand sym-naturalness. Because the present paper utilizes sem-naturalness only, Mayerthaler's distinction will not be discussed. Sem-naturalness will simply be called naturalness in the continuation of the paper. The predicate "natural" will be defined as simple (for the speaker) from the cognitive point of view. This kind of naturalness is similar to traditional markedness, and the following approximate equation can be stated as a first orientation of the reader: $\alpha$ markedness $=-\alpha$ naturalness. It is practically impossible to compare markedness and naturalness in (morpho)syntax seeing that the application of both in that field is in a state of flux.

Naturalness values will be stated in naturalness scales. The basic format is $>$ nat (A, B)-i.e., with respect to cognitive complexity, A is more natural than $\mathrm{B}$. This is the 
speaker's viewpoint. It is further assumed that, from the hearer's viewpoint, B is more natural than $\mathrm{A}$. (This is based on the assumption that the interests of the speaker and the hearer in a communicative situation are antagonistic.) Consequent$\mathrm{ly}$, the scale >nat $(\mathrm{A}, \mathrm{B})$ can be substantiated either by showing that $\mathrm{A}$ is more natural than $B$ for the speaker, or by showing that $B$ is more natural than $A$ for the hearer. However, the matter plays a minor role in this paper, and will not be elaborated.

To cover any optional usage of $\mathrm{A}$ or $\mathrm{B}$ in $>$ nat $(\mathrm{A}, \mathrm{B})$, this framework assumes the following two additional formats derived from the basic format:

(i) >nat $(\mathrm{A}+\mathrm{B}, \mathrm{B})$-i.e., with respect to cognitive complexity, the optional use of $\mathrm{A}$ (with respect to $B$ ) is more natural than the use of $B$ on its own;

(ii) >nat $(\mathrm{A}, \mathrm{A}+\mathrm{B})$-i.e., with respect to cognitive complexity, the use of $\mathrm{A}$ on its own is more natural than the optional use of $B$ (with respect to $A$ ).

Any scale in one of the two derived formats (i-ii) is asserted to be true whenever the corresponding scale in the basic format >nat $(\mathrm{A}, \mathrm{B})$ is asserted to be true. Therefore, when a scale couched in a derived format is used, it suffices to back up the corresponding scale in the basic format. Given the wealth of optional usage in languages, the applicability of my framework would be greatly reduced without the two additional formats.

In the present paper, the language examples are dealt with in "deductions". Each deduction contains at least two naturalness scales. The naturalness values of paired scales will be aligned by the principle of markedness alignment as stated in Andersen 1968 (repeated in Andersen 2001), and adapted to naturalness in the following way: what is more natural tends to align with another instance of more natural, and what is less natural tends to align with another instance of less natural.

The theory utilizes the following ways of determining naturalness in (morpho)syntax:

(a) The principle of least effort (Havers 1931:171). What conforms better to this principle is more natural. What is cognitively simple (for the speaker) is easy to produce, easy to retrieve from memory, etc.

(b) Phylogenetic age. What is older phylogenetically is more natural. What is cognitively simpler (for the speaker) is acquired earlier by the language.

(c) Prototypicality. What is nearer to the prototype is more natural.

(d) Degree of integration into the clause. What is better integrated into its clause is more natural. This partially exploits (c): the prototypical syntactic situation is for a syntactic element to be well integrated into its syntactic construction.

(e) Frequency (in the spirit of Fenk-Oczlon 1991). What is more frequent tokenand/or typewise is more natural. What is cognitively simpler (for the speaker) is used more.

(f) Small v. large class. The use of a unit pertaining to a small class is more natural than the use of a unit pertaining to a large class. During speech small classes are easier for the speaker to choose from than are large classes. 
(g) Specialised v. non-specialised use. The specialised use of a category is more natural than its non-specialised use. This generalisation is based on the following consideration. All kinds of categories occur in the most natural lexical items, paradigms and constructions of the language, and ebb on the way out of that core. Take for example a language whose noun phrases distinguish singular, plural and dual. Although singular, plural and dual are not equally natural with respect to one another, each of them is highly natural in its own field. For instance, the dual is highly natural (specialised) as an expression of duality: >nat (dual, singular/plural) / in expressions of duality. This is correlated with the circumstance that all three numbers are present in personal pronouns, i.e. in the most natural noun phrases, while they may be present to different degrees in the remaining noun phrases of the language. (Recall the above-mentioned alignment rules.) For the relevant typological data about the grammatical numbers, see Corbett (2000).

(h) Use v. non-use. The use of a category is more natural than its non-use. With this principle it is possible to fix the cutoff point between the use and non-use of a category. Because the use of a category normally (also) occurs with the most natural units of the relevant kind, the rules of alignment force the assumption that the use of a category is more natural than its non-use. E.g. >nat (+dual, -dual) / in expressions of duality. See the preceding item (g).

(i) Acceptable v. non-acceptable use. What is acceptable is more natural than what is not acceptable. The very reason for the acceptability of a syntactic unit is its greater naturalness with respect to any corresponding non-acceptable unit.

(j) What is more widespread in the languages of the world is more natural (the typological criterion). What is cognitively simpler (for the speaker) is realized in more languages.

At present time, the above items $(a-j)$ are the only ways used by the theory to determine naturalness in (morpho)syntax. In this sense the theory is highly constrained. Any recourse to additional criteria should be viewed as a weakness of the theory. (The current version of the items $(a-j)$ has resulted from cooperation with Helena Majcenovič.)

Illustrations of some of the above items $(a-j)$ will be adduced as this article proceeds.

The framework just outlined will now be applied to some (morpho)syntactic variants of English. Pairs of variants have been determined on the basis of my linguistic experience. The upper limit on the length of a variant is two linked clauses. As already mentioned, each case considered is presented in the format of a deduction. (The ordering of the deductions is mostly arbitrary.) 


\section{Examples}

The examples (these are meant to be simple and variegated) deal with various aspects of the genitive and of the pronouns.

\section{(A) The Genitive}

1. English. The genitive case shows a desinence in the singular only. (See deduction 2 for a qualification.) E.g. cat's v. cats' (Biber et al. 1999:292).

The two syntactic variants: the singular and the plural of the genitive case.

1. The assumptions of Naturalness Theory:

1.1. >nat $(+,-) /$ marked genitive case

I.e. marked (= with marking) genitive case is more natural than unmarked (= without marking) genitive case. The use of a category is more natural than its nonuse. The use of marking for case is more natural than its non-use. See item (h) in the Introduction.

\section{2. >nat (singular, plural)}

I.e. the singular is more natural than the plural (Mayerthaler 1981:15). By the principle of least effort; see item (a) in the Introduction. Whereas the plural is often encoded by special means, the singular is often left bare (in many languages).

The >nat (= high naturalness value) of scale 1.1 is the marked (= with marking) genitive case. It is aligned with the >nat of scale 1.2, which is singular. The <nat (= low naturalness value) of scale 1.1 is the unmarked (= without marking) genitive case. It is aligned with the <nat of scale 1.2, which is plural.

3. The consequences:

From 1.1-2 and 2 it can be deduced:

If there is any difference between the singular and the plural of the genitive case, such that one grammatical number marks the genitive, and the other grammatical number does not, it is the singular that tends to mark the genitive, and it is the plural that tends not to mark the genitive. Q.E.D.

As can be seen from the above deduction, my theoretical framework does not contain any generative component and operates ex post facto. I cannot predict the existence of the genitive with a desinence (cat's) and of the genitive without a desinence (cats'); I cannot predict that one kind of genitive is used in the singular, and the other kind of genitive is used in the plural. However, if this data is given, I can predict that it is in the singular that the genitive showing a desinence is used, and that it is in the plural that the genitive lacking a desinence is used. The reverse situation is not likely to obtain. It is not probable that the genitive lacking a desinence would be used in the singular, and the genitive showing a desinence would be used in the plural (if the desinence is the differentia specifica of the two genitives). It is such predictions (that is, synchronic accounts/"explanations") that constitute 
the chief motive of my work. Mutatis mutandis, these remarks apply to all deductions of the present paper.

The basic point can be stated as follows. Given two (morpho)syntactic variants, such that one of them shows feature A, and the other shows feature $B$, the theory can answer the question as to which of the two variants shows which of the two features $\mathrm{A}$ and $\mathrm{B}$.

2. English. In the plural, the genitive case equals the common case in phonological form, e.g. cats' is pronounced as cats. Only irregular plural nouns take a desinence, e.g. men's (Biber et al. 1999:292).

The two syntactic variants: the additive and the internal plural formations.

1. The assumptions of Naturalness Theory:

\section{1. >nat $(+,-) /$ marked genitive case}

I.e. the marked (= with marking) genitive case is more natural than the unmarked (= without marking) genitive case. The use of a category is more natural than its nonuse. The use of marking for case is more natural than its non-use. See item (h) in the Introduction.

1.2. >nat (internal, additive) / formation of plural

I.e. internal formation of the plural is more natural than additive formation of the plural (Mayerthaler 1981:25). The additive formation of the plural is easier for the hearer to process. The situation is the reverse for the speaker, who retrieves ready internal formations of the plural from memory. This is a natural situation by the principle of least effort; see item (a) in the Introduction.

2. Markedness agreement (Andersen 2001) applied to naturalness:

2.1. $>$ nat tends to align with another $>$ nat

2.2. <nat tends to align with another $<$ nat

3. The consequences:

From $1.1-2$ and 2 it can be deduced:

If there is any difference between additive and internal plural-noun formations, such that one formation marks the genitive, and the other formation does not, it is the internal plural formation that tends to mark the genitive, and it is the additive plural formation that tends not to mark the genitive. Q.E.D.

3. English. Specifying genitives, e.g. the girl's face, are prevailingly definite. Classifying genitives, e.g. a bird's nest, are prevailingly indefinite (Biber et al. 1999:294-5).

The two syntactic variants: specifying and classifying genitives.

1. The assumptions of Naturalness Theory:

1.1. >nat (specifying, classifying) / genitive

I.e. a specifying genitive is more natural than a classifying genitive. The specifying function is the most important function of the genitive (Biber et al. 1999:294). 
Thus the specifying function is very likely the prototypical function of the genitive. See item (c) of the Introduction.

\section{2. >nat $(+,-) /$ definite NP}

I.e. a definite noun phrase is more natural than an indefinite noun phrase. A definite noun phrase is more accessible for the speaker than an indefinite noun phrase. By the principle of least effort; see item (a) in the Introduction.

2. Markedness agreement (Andersen 2001) applied to naturalness:

2.1. >nat tends to align with another $>$ nat

2.2. <nat tends to align with another <nat

3. The consequences:

From $1.1-2$ and 2 it can be deduced:

If there is any difference between specifying and classifying genitives, such that one kind of genitive is prevailingly definite, and the other indefinite, it is the specifying genitives that tend to be definite, and it is the classifying genitives that tend to be indefinite. Q.E.D.

4. English. The classifying genitives commonly occur in the plural, e.g. boys' camp (Biber et al. 1999:295).

The two syntactic variants: the specifying and the classifying genitives.

1. The assumptions of Naturalness Theory:

1.1. >nat (specifying, classifying) / genitive

I.e. a specifying genitive is more natural than a classifying genitive. The specifying function is the most important function of the genitive (Biber et al. 1999:294). Thus the specifying function is very likely the prototypical function of the genitive. See item (c) of the Introduction.

\section{2. >nat (singular, plural)}

I.e. the singular is more natural than the plural (Mayerthaler 1981:15). By the principle of least effort; see item (a) in the Introduction; whereas the plural is often encoded by special means, the singular is often left bare (in many languages).

A special case of 1.2:

1.2.1. >nat (singular \& plural, only plural)

I.e. admitting both the singular and the plural is more natural than admitting only the plural. The scale has the format >nat $(\mathrm{A}+\mathrm{B}, \mathrm{B})$; see the Introduction.

2. Markedness agreement (Andersen 2001) applied to naturalness:

2.1. $>$ nat tends to align with another $>$ nat

2.2. <nat tends to align with another <nat

3. The consequences:

From 1.1, 1.2.1 and 2 it can be deduced:

If there is any difference between the specifying and the classifying genitives, such that one kind of genitive is used both in the singular and in the plural, and the other kind of genitive is used only in the plural, it is the specifying genitives that tend 
to be used both in the singular and in the plural, and it is the classifying genitives that tend to be used only in the plural. Q.E.D.

5. English. Whereas specifying genitives can be paraphrased by an of-phrase, e.g. the girl's face - the face of the girl, classifying genitives are frequently paraphrased by a forphrase, e.g. children's clothes - clothes for children (Biber et al. 1999:294-5).

The two syntactic variants: the specifying and the classifying genitives.

1. The assumptions of Naturalness Theory:

1.1. >nat (specifying, classifying) / genitive

I.e. a specifying genitive is more natural than a classifying genitive. The specifying function is the most important function of the genitive (Biber et al. 1999:294). Thus the specifying function is very likely the prototypical function of the genitive. See item (c) of the Introduction.

1.2. >nat (the type the face of the girl, the type clothes for children)

I.e. the type the face of the girl is more natural than the type clothes for children. For is a more specific preposition than of, therefore more satisfactory than of for the hearer. The situation is the reverse for the speaker; see the Introduction.

2. Markedness agreement (Andersen 2001) applied to naturalness:

2.1. $>$ nat tends to align with another $>$ nat

2.2. <nat tends to align with another $<$ nat

3. The consequences:

From $1.1-2$ and 2 it can be deduced:

If there is any difference between specifying and classifying genitives, such that one kind of genitive can be paraphrased by an of-phrase, and the other kind by a forphrase, it is the specifying genitives that tend to be paraphrased by an of-phrase, and it is the classifying genitives that tend to be paraphrased by a for-phrase. Q.E.D.

6. English. Elliptic genitives - such as in That isn't my handwriting. It's Selina's! - are mostly specifying (Biber et al. 1999:296-7).

The two syntactic variants: specifying and classifying genitives.

1. The assumptions of Naturalness Theory:

1.1. >nat (specifying, classifying) / genitive

I.e. a specifying genitive is more natural than a classifying genitive. The specifying function is the most important function of the genitive (Biber et al. 1999:294). Thus the specifying function is very likely the prototypical function of the genitive. See item (c) of the Introduction.

1.2. >nat $(+,-)$ / ellipted head noun of genitive

I.e. an ellipted head noun of the genitive is more natural than a non-ellipted head noun of the genitive. By the principle of least effort; see item (a) in the Introduction.

A special case of 1.2 :

1.2.1. >nat $(+/-,-) /$ ellipted head noun of genitive 
I.e. a genitive admitting ellipted and non-ellipted head nouns is more natural than a genitive admitting only non-ellipted head nouns. The scale has the format $>$ nat $(\mathrm{A}+\mathrm{B}, \mathrm{B})$; see the Introduction.

2. Markedness agreement (Andersen 2001) applied to naturalness:

2.1. $>$ nat tends to align with another $>$ nat

2.2. <nat tends to align with another <nat

3. The consequences:

From 1.1, 1.2.1 and 2 it can be deduced:

If there is any difference between specifying and classifying genitives, such that one kind of genitive associates with ellipted and non-ellipted head nouns, and the other kind associates with non-ellipted head nouns, it is the specifying genitives that tend to associate with ellipted and non-ellipted head nouns, and it is the classifying genitives that tend to associate with non-ellipted head nouns. Q.E.D.

7. English. Many independent genitives have become conventionalized, so that they need no supporting head noun in the context, e.g. she's going to a friend's. Independent genitives are found particularly in conversation (Biber et al. 1999:297, 300). The present deduction is continued in deduction 8 .

The two variants: conversation and the written registers.

1. The assumptions of Naturalness Theory:

1.1. >nat (conversation, written registers)

I.e. conversation is more natural than the written registers (Dotter 1990:228). Oral communication is the primary form of communication.

1.2. >nat $(+,-)$ / ellipted head noun of genitive

I.e. an ellipted head noun of the genitive is more natural than a non-ellipted head noun of the genitive. By the principle of least effort; see item (a) in the Introduction.

A special case of 1.2 :

1.2.1. >nat $(+/-,-) /$ ellipted head noun of genitive

I.e. a genitive admitting ellipted and non-ellipted head nouns is more natural than a genitive admitting only non-elliptable head nouns. The scale has the format $>$ nat $(\mathrm{A}+\mathrm{B}, \mathrm{B})$; see the Introduction.

2. Markedness agreement (Andersen 2001) applied to naturalness:

2.1. $>$ nat tends to align with another $>$ nat

2.2. <nat tends to align with another <nat

3. The consequences:

From 1.1, 1.2.1 and 2 it can be deduced:

If there is any difference between conversation and the written registers, such that one kind of register admits genitives with ellipted and non-ellipted head nouns, and the other kind of register admits only genitives with non-ellipted head nouns, it is conversation that tends to admit genitives with both ellipted and non-ellipted head 
nouns, and it is the written registers that tend to admit only genitives with non-ellipted head nouns. Q.E.D.

8. English. Many independent genitives have become conventionalized, so that they need no supporting head noun in the context, e.g. she's going to a friend's. Independent genitives are found particularly in conversation (Biber et al. 1999:297, 300). The present deduction continues deduction 7 .

The two syntactic variants: genitive with ellipted head noun, and genitive with non-ellipted head noun.

1. The assumptions of Naturalness Theory:

1.1. >nat $(+,-)$ / formula

I.e. formulas are more natural than non-formulas. Formulas support the principle of least effort. See item (a) in the Introduction.

1.2. >nat $(+,-) /$ ellipted head noun of genitive

I.e. an ellipted head noun of the genitive is more natural than a non-ellipted head noun of the genitive. By the principle of least effort; see item (a) in the Introduction. 2. Markedness agreement (Andersen 2001) applied to naturalness:

2.1. $>$ nat tends to align with another $>$ nat

2.2. $<$ nat tends to align with another $<$ nat

3. The consequences:

From $1.1-2$ and 2 it can be deduced:

If there is any difference between a genitive with ellipted head noun and a genitive with non-ellipted head noun, such that one kind of genitive is used in formulas, and the other not, it is the genitive with ellipted head noun that tends to be used in formulas, and it is the genitive with non-ellipted head noun that tends to be used in non-formulas. Q.E.D.

9. English. The definite article does not normally combine with the head noun of a double genitive. E.g. a good idea of Johnny's as against Johnny's good idea (Biber et al. 1999:299).

The two syntactic variants: the type a good idea of Johnny's, and the type Johnny's good idea.

1. The assumptions of Naturalness Theory:

1.1. >nat (the type Johnny's good idea, the type a good idea of Johnny's)

I.e. the type Johnny's good idea is more natural than the type a good idea of Johnny's. By the principle of least effort; see item (a) in the Introduction.

1.2. >nat $(+,-) /$ definite

I.e. +definite is more natural than -definite. Anything +definite is easier for the speaker to retrieve from memory than anything -definite. By the principle of least effort; see item (a) in the Introduction.

2. Markedness agreement (Andersen 2001) applied to naturalness: 
2.1. >nat tends to align with another $>$ nat

2.2. <nat tends to align with another <nat

3. The consequences:

From 1.1-2 and 2 it can be deduced:

If there is any difference between the type a good idea of Johnny's and the type Johnny's good idea, such that one type is +definite, and the other type is -definite, it is the type Johnny's good idea that tends to be +definite, and it is the type a good idea of Johnny's that tends to be -definite. Q.E.D.

10. English. Plural nouns prefer the prepositional genitive to the Saxon genitive. Singular nouns prefer the Saxon genitive to the prepositional one (Biber et al. 1999:303).

The two syntactic variants: the prepositional and the Saxon genitives.

1. The assumptions of the Naturalness Theory:

1.1. >nat (Saxon genitive, prepositional genitive)

I.e. the Saxon genitive is more natural than the prepositional genitive. By the principle of least effort; see item (a) in the Introduction.

1.2. >nat (singular, plural)

I.e. the singular is more natural than the plural (Mayerthaler 1981:15). By the principle of least effort; see item (a) in the Introduction; while the plural is often encoded by special means, the singular is often left bare (in many languages).

2. Markedness agreement (Andersen 2001) applied to naturalness:

2.1. $>$ nat tends to align with another $>$ nat

2.2. <nat tends to align with another < nat

3. The consequences:

From $1.1-2$ and 2 it can be deduced:

If there is any difference between the prepositional and Saxon genitives, such that one genitive is used in the singular, and the other genitive is used in the plural, it is the Saxon genitive that tends to occur in the singular, and it is the prepositional genitive that tends to occur in the plural. Q.E.D.

11. English. In contradistinction to the prepositional genitive, the Saxon genitive is frequently used in formulaic expressions (collocations) such as life's work, for God's sake, and numerous other combinations with sake (Biber et al. 1999:306).

The two syntactic variants: the prepositional and the Saxon genitives.

1. The assumptions of Naturalness Theory:

1.1. >nat (Saxon genitive, prepositional genitive)

I.e. the Saxon genitive is more natural than the prepositional genitive. By the principle of least effort; see item (a) in the Introduction.

1.2. >nat $(+,-) /$ formula 
I.e. formulas are more natural than non-formulas. Formulas support the principle of least effort. See item (a) in the Introduction.

A special case of 1.2 :

\subsection{1. >nat $(+/-,-) /$ formula}

I.e. admitting formulas is more natural than not admitting them. The scale has the format $>$ nat $(\mathrm{A}+\mathrm{B}, \mathrm{B})$; see the Introduction.

2. Markedness agreement (Andersen 2001) applied to naturalness:

2.1. $>$ nat tends to align with another $>$ nat

2.2. <nat tends to align with another <nat

3. The consequences:

From 1.1, 1.2.1 and 2 it can be deduced:

If there is any difference between the prepositional and the Saxon genitives, such that one genitive can be used in formulas, and the other genitive cannot, it is the Saxon genitive that tends to admit formulas, and it is the prepositional genitive that tends not to be used in formulas. Q.E.D.

12. English. The type a friend of hers (containing a possessive pronoun, i.e. a pronominal noun phrase) is more frequent than the type a friend of John's (containing a nonpronominal noun phrase) (Biber et al. 1999:308).

The two syntactic variants: the type $a$ friend of John's and the type $a$ friend of hers. 1. The assumptions of Naturalness Theory:

1.1. >nat (the type a friend of hers, the type a friend of John's)

I.e. the type $a$ friend of hers is more natural than the type a friend of John's. By the principle of least effort; see item (a) in the Introduction.

1.2. >nat (more frequent, less frequent) / unit

I.e. a more frequent unit is more natural than a less frequent unit. See item (e) in the Introduction.

2. Markedness agreement (Andersen 2001) applied to naturalness:

2.1. $>$ nat tends to align with another $>$ nat

2.2. <nat tends to align with another $<$ nat

3. The consequences:

From $1.1-2$ and 2 it can be deduced:

If there is any difference between the type a friend of John's and the type a friend of hers, such that one type is common, and the other type is less common, it is the type $a$ friend of hers that tends to be common, and it is the type a friend of John's that tends to be less common. Q.E.D. 
(B) Pronouns

13. English. The personal pronouns of the third person: in the singular, three pronouns are used, he, she and $i t$, whereas in the plural only one pronoun is used, namely they (Biber et al. 1999:328).

The two syntactic variants: the personal pronouns of the third person singular, and the personal pronouns of the third person plural.

1. The assumptions of Naturalness Theory:

1.1. >nat (three, one) / number of personal pronouns per one number of the third person

I.e. having three personal pronouns in one number of the third person is more natural than having only one personal pronoun in one number of the third person. One personal pronoun in one number of the third person is easier for the hearer to process. The situation is the reverse for the speaker; see the Introduction.

1.2. >nat (singular, plural)

I.e. the singular is more natural than the plural (Mayerthaler 1981:15). By the principle of least effort; see item (a) in the Introduction; while the plural is often encoded by special means, the singular is often left bare (in many languages).

2. Markedness agreement (Andersen 2001) applied to naturalness:

2.1. $>$ nat tends to align with another $>$ nat

2.2. <nat tends to align with another $<$ nat

3. The consequences:

From 1.1-2 and 2 it can be deduced:

If there is any difference, within the personal pronouns of the third person, between the singular and plural, such that one number has three pronouns, and the other number has one pronoun, it is the singular that tends to have three pronouns, and it is the plural that tends to have one pronoun only. Q.E.D.

14. English. The personal pronouns of the third person singular: he and she have personal reference, and it has mostly non-personal reference (Biber et al. 1999:328).

The two syntactic variants: the personal pronouns of the third person singular with personal and non-personal reference.

1. The assumptions of Naturalness Theory:

1.1. >nat (two, one) / third-person singular personal pronouns

I.e. having two personal pronouns in the third person singular is more natural than having only one personal pronoun in the third person singular. One personal pronoun in the third person singular is easier for the hearer to process than two personal pronouns in that person. The situation is the reverse for the speaker; see the Introduction.

1.2. >nat $(+,-)$ / human 
I.e. thuman is more natural than -human (Mayerthaler 1981:14). The speaker is more interested in anything human than in anything non-human.

2. Markedness agreement (Andersen 2001) applied to naturalness:

2.1. $>$ nat tends to align with another $>$ nat

2.2. <nat tends to align with another <nat

3. The consequences:

From $1.1-2$ and 2 it can be deduced:

If there is any difference, within the personal pronouns of the third person singular, between thuman and -human, such that one kind has two pronouns, and the other kind has only one pronoun, it is thuman that tends to have two pronouns, and it is -human that tends to have one pronoun only. Q.E.D.

15. English. In conversation, nominative personal pronouns are often repeated,

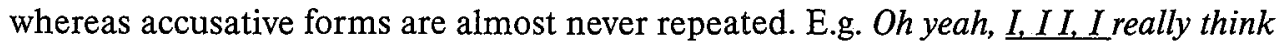
that you can just go (Biber et al. 1999:334).

The two syntactic variants: the nominative and the accusative of the personal pronouns, in conversation.

1. The assumptions of Naturalness Theory:

1.1. >nat (nominative, accusative) / in nom.-acc. languages

I.e. the nominative is more natural than the accusative, in nominative-accusative languages (Mayerthaler 1981:14; 1987:41; Mayerthaler et al. 1998:167). Crosslinguistically, the accusative is sometimes encoded with an adposition, the nominative never.

1.2. >nat (much, little) / repetition

I.e. much repetition is more natural than little repetition. Repetition, being imitation, is an innate property of human beings ( $\mathrm{Li}$ 1986:40-1).

2. Markedness agreement (Andersen 2001) applied to naturalness:

2.1. $>$ nat tends to align with another $>$ nat

2.2. $<$ nat tends to align with another $<$ nat

3. The consequences:

From $1.1-2$ and 2 it can be deduced:

If there is any difference, in conversation, between the nominative and the accusative of the personal pronouns, such that one kind is often repeated, and the other is hardly repeated, it is the nominative that tends to be repeated, and it is the accusative that tends not to be repeated. Q.E.D.

16. English. In conversation, the expected nominative forms of personal pronouns are replaced by the corresponding accusative forms after $B E$, as and than, frequently in coordinated noun phrases, and normally in peripheral and non-integrated noun phrases, e.g. it's me, I'm dozing even better than him, me and this other bloke managed to avoid each other; me, I was early (Biber et al. 1999:335-40). In my opinion, the 
nominative forms tend to be replaced by the accusative forms when the forms are accented (but not necessarily emphatic). As is well known, the subject pronouns of Germanic languages are as a rule not accented.

The two syntactic variants: nominative and accusative forms of personal pronouns.

1. The assumptions of Naturalness Theory:

1.1. >nat (nominative, accusative) / in nom.-acc. languages

I.e. the nominative is more natural than the accusative, in nominative-accusative languages (Mayerthaler 1981:14; 1987:41; Mayerthaler et al. 1998:167). Crosslinguistically, the accusative is sometimes encoded with an adposition, but the nominative never.

1.2. >nat $(-,+) /$ accented word

I.e. an unaccented word is more natural than an accented word. By the principle of least effort; see item (a) in the Introduction.

2. Markedness agreement (Andersen 2001) applied to naturalness:

2.1. $>$ nat tends to align with another $>$ nat

2.2. <nat tends to align with another <nat

3. The consequences:

From $1.1-2$ and 2 it can be deduced:

If there is any difference between the expected nominative and the accusative forms of personal pronouns, such that one kind is used when the pronouns are accented, and the other kind is used when the pronouns are not accented, it is the nominative form that tends to be used when the pronoun is not accented, and it is the accusative form that tends to be used when the pronoun is accented. Q.E.D.

4. Note to item 3 . The accusative forms can be replaced by the corresponding reflexive pronouns, e.g. Rose and her, also Rose and herself (Biber et al. 1999:343).

17. English. The pronominal possessives have two forms each: a possessive determiner, e.g. $m y$, and a possessive pronoun, e.g. mine. An exception is its, which is used as determiner only (Biber et al. 1999:340). This deduction is continued in deduction 18.

The two syntactic variants: the determiner and the pronoun use of the pronominal possessives.

1. The assumptions of Naturalness Theory:

1.1. >nat (the type $m y$, the type mine)

I.e. the type $m y$ is more natural than the type mine. Within pronominal possessives, the determiners have less sound body and internal structure than the pronouns, therefore they abide by the principle of least effort; see item (a) in the Introduction.

1.2. >nat (determiner, pronoun) / pronominal possessive 
I.e. a pronominal possessive having determiner uses is more natural than a pronominal possessive having pronoun uses. Determiners are better integrated into the clause (being integrated into a phrase) than pronouns. See item (d) in the Introduction.

2. Markedness agreement (Andersen 2001) applied to naturalness:

2.1. $>$ nat tends to align with another $>$ nat

2.2. <nat tends to align with another $<$ nat

3. The consequences:

From $1.1-2$ and 2 it can be deduced:

If there is any difference, within pronominal possessives, between the type my and the type mine, such that one type is used as a pronoun, and the other type is used as a determiner, it is the type my that tends to be used as a determiner, and it is the type mine that tends to be used as a pronoun. Q.E.D.

18. English. The pronominal possessives have two forms each: a possessive determiner, e.g. $m y$, and a possessive pronoun, e.g. mine. An exception is its, which is used as determiner only (Biber et al. 1999:340). This deduction continues deduction 17.

The two syntactic variants: the acceptable determiner use and unacceptable pronoun use of the pronominal possessive its.

1. The assumptions of Naturalness Theory:

1.1. >nat (determiner, pronoun) / pronominal possessive

I.e. a pronominal possessive having determiner uses is more natural than a pronominal possessive having pronoun uses. Within pronominal possessives, determiners have less sound body and internal structure than pronouns in English, therefore they abide by the principle of least effort; see item (a) in the Introduction. Moreover, determiners are better integrated into the clause (being integrated into a phrase) than pronouns. See item (d) in the Introduction.

1.2. >nat $(+,-) /$ acceptable

I.e. being acceptable is more natural than being unacceptable. See item (i) in the Introduction.

2. Markedness agreement (Andersen 2001) applied to naturalness:

2.1. $>$ nat tends to align with another $>$ nat

2.2. <nat tends to align with another $<$ nat

3. The consequences:

From 1.1-2 and 2 it can be deduced:

If there is any difference between the determiner use and the pronoun use of the pronominal possessive its, such that one use is acceptable, and the other use is not acceptable, it is the determiner use that tends to be acceptable, and it is the pronoun use that tends to be unacceptable. Q.E.D. 
19. English. The emphatic reflexive pronoun mostly stands beside its noun phrase, which is normally the subject, e.g. myself, I don't know. In conversation, the reflexive pronoun stands separated from its noun phrase, usually at the end of the clause, e.g. I'll do it myself (Biber et al. 1999:344).

The two syntactic variants: the type I'll do it myself and the type myself, I don't know.

1. The assumptions of Naturalness Theory:

1.1. >nat (the type I'll do it myself, the type myself, I don't know)

I.e. the type I'll do it myself is more natural than the type myself, I don't know. The type myself, I don't know is easier for the hearer to process because the reflexive pronoun and the corresponding noun phrase are contiguous. The situation is the reverse for the speaker; see the Introduction. Also, myself is better integrated into its clause in I'll do it myself, and thus the latter is more natural; see item (d) of the Introduction.

\section{2. >nat (conversation, written registers)}

I.e. conversation is more natural than the written registers (Dotter 1990, 228). Oral communication is the primary form of communication.

2. Markedness agreement (Andersen 2001) applied to naturalness:

2.1. $>$ nat tends to align with another $>$ nat

2.2. <nat tends to align with another <nat

3. The consequences:

From $1.1-2$ and 2 it can be deduced:

If there is any difference between the type I'll do it myself and the type myself, I don't know, such that one of them is used in conversation, and the other in the written registers, it is the type I'll do it myself that tends to occur in conversation, and it is the type myself, I don't know that tends to occur in the written registers. Q.E.D.

20. English. Demonstrative pronouns normally cannot refer to persons, whereas demonstrative determiners, e.g. this man, can (Biber et al. 1999:347).

The two syntactic variants: demonstrative pronouns and determiners.

1. The assumptions of the Naturalness Theory:

1.1. >nat (determiner, pronoun) / demonstrative

I.e. the determiner use of a demonstrative is more natural than the pronoun use of a demonstrative. Determiners are better integrated into the clause (being integrated into a phrase of the clause) than pronouns. See item (d) in the Introduction. 1.2. >nat $(+,-) /$ human referent

I.e. a human referent is more natural than a non-human referent. This is in line with the animacy hierarchy (Croft 1990:112).

A special case of 1.2:

1.2.1. >nat $(+/-,-) /$ human referent 
I.e. admitting human referents is more natural than not admitting them. The scale has the format $>$ nat $(\mathrm{A}+\mathrm{B}, \mathrm{B})$; see the Introduction.

2. Markedness agreement (Andersen 2001) applied to naturalness:

2.1. >nat tends to align with another $>$ nat

2.2. <nat tends to align with another <nat

3. The consequences:

From 1.1, 1.2.1 and 2 it can be deduced:

If there is any difference between the determiner use of a demonstrative and the pronoun use of a demonstrative, such that one use can refer to human referents, and the other use cannot, it is the determiner use that tends to admit human referents, and it is the pronoun use that tends not to admit human referents. Q.E.D.

21. English. The reciprocal pronoun each other is much more common than the reciprocal pronoun one another. Each other is strongly preferred when the reference is to two entities (Biber et al. 1999:346-7).

The two syntactic variants: the reciprocal pronouns each other and one another.

1. The assumptions of Naturalness Theory:

1.1. >nat (each other, one another) / reciprocal pronoun

I.e. the reciprocal pronoun each other is more natural than the reciprocal pronoun one another. This is based on the relative frequencies of the two pronouns, mentioned above. See item (e) in the Introduction.

1.2. >nat (two entities, more than two entities) / involved in reciprocity

I.e. only two entities involved in reciprocity is more natural than more than two entities involved in reciprocity. This is based on the real-life circumstance that classes of two interacting entities are more common than classes of more than two interacting entities. See item (e) in the Introduction.

2. Markedness agreement (Andersen 2001) applied to naturalness:

2.1. $>$ nat tends to align with another $>$ nat

2.2. <nat tends to align with another <nat

3. The consequences:

From $1.1-2$ and 2 it can be deduced:

If there is any difference between the reciprocal pronouns each other and one another, such that one of them is preferred when the reference is to two entities, and the other when the reference is to more than two entities, it is the reciprocal pronoun each other that tends to be used when the reference is to two entities, and it is the reciprocal pronoun one another that tends to be used when the reference is to more than two entities. Q.E.D.

22. English. The reference of the demonstrative pronoun to countable entities can be clarified by the addition of one(s), e.g. I like this one. This use is particularly common in conversation (Biber et al. 1999:348). 
The two syntactic variants: the type this/that (referring to countable and uncountable entities), and the type this/that one (referring to countable entities).

1. The assumptions of Naturalness Theory:

1.1. >nat (the type this/that one, the type this/that + NP)

I.e. the type this/that one is more natural than the type this/that + noun phrase other than one. By the principle of least effort; see item (a) in the Introduction.

1.2. >nat $(+,-) /$ countable

I.e. a countable unit is more natural than an uncountable unit. This is the case in languages with i-perspective (Mayerthaler et al. 1998:392).

A special case of 1.2:

1.2.1. >nat (countable, countable \& uncountable)

I.e. referring to countable entities only is more natural than referring both to countable and uncoutable entities. The scale has the format >nat $(A, A+B)$; see the Introduction.

1.3. >nat (conversation, the written registers)

I.e. conversation is more natural than the written registers (Dotter 1990:228). Oral communication is the primary form of communication.

A special case of 1.3:

1.3.1. >nat (conversation, conversation $\&$ the written registers)

I.e. occurring in conversation only is more natural than occurring both in conversation and the written registers. The scale has the format >nat $(A, A+B)$; see the Introduction.

2. Markedness agreement (Andersen 2001) applied to naturalness:

2.1. $>$ nat tends to align with another $>$ nat

2.2. <nat tends to align with another <nat

3. The consequences:

From 1.1, 1.2.1, 1.3.1 and 2 it can be deduced:

If there is any difference between the type this/that one and the type this/that + noun phrase, such that one type refers both to countable and to uncountable entities, and the other type refers only to countable entities, and such that one type occurs in conversation, and the other type occurs both in conversation and the written registers, it is the type this/that one that tends to refer only to countable entities, and to be used only in conversation, and it is the type this/that + noun phrase that tends to refer both to countable and to uncountable entities, and tends to be used both in conversation and the written registers. Q.E.D.

23. English. In conversation, the pronoun that is by far the single most common demonstrative pronoun (Biber et al. 1999:349-51).

The two syntactic variants: the pronoun that in conversation and in the written registers.

1. The assumptions of Naturalness Theory: 


\section{1. >nat (vague, precise) / uses of demonstrative pronouns}

I.e. vague uses of demonstrative pronouns are more natural than precise uses of demonstrative pronouns. It is easier for the hearer to process precise uses. The situation is the reverse for the speaker; see the Introduction.

A special case of 1.1:

1.1.1. >nat (that, other) / demonstrative pronoun

I.e. the demonstrative pronoun that is more natural than other demonstrative pronouns. In contradistinction to other demonstrative pronouns, the demonstrative pronoun that has vague uses in conversation; it is "usually fairly vague" (Biber et al. 1999:350).

\section{2. >nat $(+,-)$ / frequent}

I.e. being frequent is more natural than being less frequent. See item (e) in the Introduction.

2. Markedness agreement (Andersen 2001) applied to naturalness:

2.1. >nat tends to align with another $>$ nat

2.2. <nat tends to align with another <nat

3. The consequences:

From 1.1.1, 1.2 and 2 it can be deduced:

If there is any difference, in conversation, between that and other demonstrative pronouns, such that one kind of demonstrative pronoun is frequent, and the other kind of demonstrative pronoun less frequent, it is that that tends to be frequent, and it is the other demonstrative pronouns that tend to be less frequent. Q.E.D.

24. English. There is a special conversational use of the demonstrative determiners this/these, where they introduce new information, especially in telling a story or introducing a new topic, e.g. there was this really good looking bloke (Biber et al. 1999:274).

The two variants: conversation and the written registers.

1. The assumptions of Naturalness Theory:

1.1. >nat (conversation, the written registers)

I.e. conversation is more natural than the written registers (Dotter 1990:228). Oral communication is the primary form of communication.

1.2. >nat (old, new) / information

I.e. old information is more natural than new information. Old information is easier for the speaker to handle. By the principle of least effort; see item (a) in the Introduction.

A special case of 1.2:

1.2.1. >nat (new, old) / information conveyed by demonstrative determiner THIS.

I.e. new information is more natural than old information if conveyed by the demonstrative determiner THIS. Markedness reversal has been applied to scale 1.2, 
because the environment of the scale was narrowed to the demonstrative determiner THIS. See the Introduction and item 4 . Note below.

A special case of 1.2.1:

1.2.1.1. >nat (new \& old, only old) / information conveyed by demonstrative determiner THIS.

I.e. new and old information is more natural than only old information if conveyed by the demonstrative determiner THIS. The scale has the format $>$ nat $(\mathrm{A}+\mathrm{B}$, B); see the Introduction.

2. Markedness agreement (Andersen 2001) applied to naturalness:

2.1. >nat tends to align with another $>$ nat

2.2. <nat tends to align with another <nat

3. The consequences:

From 1.1, 1.2.1.1 and 2 it can be deduced:

If there is any difference between conversation and the written registers, such that in one kind of register the demonstrative determiner THIS conveys either old or new information, and in the other kind of register the demonstrative determiner THIS conveys only old information, it is in conversation that the demonstrative determiner THIS tends to convey either old or new information, and it is in the written registers that the demonstrative determiner THIS tends to convey only old information. Q.E.D.

4. Note. The scale, >nat (THE, THIS) / determiner, shows that THIS is the less natural kind of determiner, by the principle of least effort; see item (a) in the Introduction.

\section{Conclusion}

In the Consequences of each deduction, a state of affairs is predicted. What is predicted to be such-and-such a state of affairs cannot be otherwise. (In particular, the state of affairs is not likely to be the reverse of what it is.) In this sense, each state of affairs subsumed in the Consequences is accounted for ("explained" in synchronic terms).

It can likewise be seen in each deduction which assumptions couched in naturalness scales can lead to the corresponding prediction. The creative contribution of the linguist determines which scales are implemented, and in which of the three available scale formats. (In this connection, the essential fact is that the choice of the linguist's possibilities is severely limited.) It is conceivable that the same prediction can be deduced from several alternative sets of assumptions. This potential has not been exploited above. 


\section{References}

ANDERSEN, H. 1968: IE. ${ }^{*} s$ after $i, u, r, k$ in Baltic and Slavic. Acta Linguistica Hafniensia 11, 171-190.

ANDERSEN, H. 2001: Markedness and the theory of linguistic change. Andersen, H. (ed.): Actualization: Linguistic change in progress. Amsterdam: Benjamins, 21-57.

BiBer, D., S. JohANSSON, G. LEECH, S. CONRAD \& E. FineGAN 1999: Longman grammar of spoken and written English. London: Longman.

CoRBeTt, G. G. 2000: Number. Cambridge: Cambridge University Press.

CROFT, W. 1990: Typology and universals. Cambridge: Cambridge University Press.

DoTTER, F. 1990: Nichtarbitrarität und lkonizität in der Syntax. Hamburg: Buske.

DRESSLER, W. U., W. MAYERTHALER, O. PANAGL \& W. U. WURzEL. 1987: Leitmotifs in natural morphology. Amsterdam: Benjamins.

DREssLeR, W. U. 2000: Naturalness. Booij, G., Chr. Lehmann \& J. Mugdan (eds.): Morphologie: ein internationales Handbuch zur Flexion und Wortbildung, Volume I. Berlin: de Gruyter, 288-296.

Fenk-Oczlon, G. 1991: Frequenz und Kognition - Frequenz und Markiertheit. Folia Linguistica 25, 361-394.

HAVERS, W. 1931: Handbuch der erklärenden Syntax. Heidelberg: Winter.

LI, C. N. 1986: Direct and indirect speech: A functional study. Coulmas, F. (ed.): Direct and indirect speech. Berlin: Mouton de Gruyter, 29-45.

MAYERTHALER, W. 1981: Morphologische Natürlichkeit. Wiesbaden: Athenaion.-English version: Mayerthaler 1988.

MAYERTHALER, W. 1987: System-independent morphological naturalness. Dressler, W. U., W. Mayerthaler, O. Panagl \& W. U. Wurzel: Leitmotifs in natural morphology. Amsterdam: Benjamins, 25-58.

MAYERTHALER, W. 1988: Morphological naturalness. Ann Arbor: Karoma.

MAYERTHALER, W. \& G. Fliedl. 1993: Natürlichkeitstheoretische Syntax. Jacobs, J., A. von Stechow, W. Sternefeld \& T. Vennemann (eds.): Syntax, Volume I. Berlin: de Gruyter, 610-635.

MAYERTHAlER, W., G. Fliedl \& Chr. Winkler. 1993: Infinitivprominenz in europäischen Sprachen. Teil I: Die Romania (samt Baskisch). Tübingen: Narr.

MAYERTHALER, W., G. Fliedl \& Chr. Winkler. 1995: Infinitivprominenz in europäischen Sprachen. Teil II: Der Alpen-Adria-Raum als Schnittstelle von Germanisch, Romanisch und Slawisch. Tübingen: Narr.

MAYERTHALER, W., G. FLIEDL \& Chr. WINKLER. 1998: Lexikon der natürlichkeitstheoretischen Syntax und Morphosyntax. Tübingen: Stauffenburg.

WURZEL, W. U. 1984: Flexionsmorphologie und Natürlichkeit. Berlin: Akademie-Verlag. 


\section{Povzetek}

\section{JEZIKOVNA NARAVNOST V ANGLEŠČINI - (A) RODILNIK, (B) ZAIMKI}

V Sloveniji smo naravno skladnjo celovške šole razširili na raziskave vedenja sopomenskih in domala sopomenskih (obliko)skladenjskih izrazov, tu imenovanih skladenjske dvojnice. Naše delo je zgoraj ponazorjeno z (obliko)sklađnjo angleškega rodilnika in angleških zaimkov. Jezikovno gradivo se obravnava $v$ t.i. izpeljavah. $V$ vsaki izpeljavi je napovedan obstoj nekih (obliko)skladenjskih razmer, in sicer na podlagi primernih predpostavk in Andersenovih pravil o prirejanju ene vrednosti zaznamovanosti drugi taki vrednosti.

Temeljni dosežek teorije: če sta dani dve (obliko)skladenjski dvojnici, od katerih ima ena lastnost $A$, druga pa lastnost $B$, zmore teorija odgovoriti na vprašanje, katera izmed obeh dvojnic ima katero izmed lastnosti $\mathrm{A}$ in $\mathrm{B}$. 